\title{
Reflexões sobre o Acolhimento de Profissionais de Saúde na Pandemia
}

Reflections about the Psychological Attention of Health Workers in the Pandemic Reflexiones sobre la Acogida de Trabajadores Sanitarios en la Pandemia

\author{
Ana Luiza Fernandes Furtado \\ Déborah David Pereira \\ Hugo Ribeiro Lanza \\ Mateus Fonte Boa Viana \\ Paula Cristina Carneiro do Prado \\ Mariana Pereira Santos \\ Tereza Cristina Peixoto
}

Universidade Federal de Minas Gerais (UFMG), Belo Horizonte, MG, Brasil

\section{Lucas Henrique de Carvalho \\ Camila Dulce Gorgulho Campos \\ Daniele Souza Steglich \\ Gabriela Cunha Gonçalves}

Hospital das Clínicas da Universidade Federal de Minas Gerais (HC-UFMG), Belo Horizonte, MG, Brasil

\section{Resumo}

O presente artigo tem como objetivo, por meio de um relato de experiência, compartilhar reflexõesa respeito das ações de um projeto de extensão realizado em 2020 com o intuito de fortalecer trabalhadores de saúde durante a pandemia da Covid-19. Estudantes de psicologia, psicólogos residentes e uma docente participaram da experiência, oferecendo acolhimento psicológico a treze trabalhadoras de instituições públicas de saúde, em sua maioria profissionais da enfermagem, que buscaram o projeto por demanda espontânea. Durante os encontros, estimulou-se a análise do cotidiano do trabalho e dos mecanismos de enfrentamento individuais e coletivos, metodologia baseada na Ergologia. Os temas convergentes nos acolhimentos foram: senso de responsabilidade, sentimento de culpa e sofrimento no trabalho; risco de contaminação, distanciamento social e estigmas; gestão do trabalho e humanização do cuidado. Por fim, considera-se a importância do projeto para o suporte e reflexão crítica das trabalhadoras sobre os processos de trabalho.

Palavras-chave: Saúde mental; COVID-19; Saúde do trabalhador.

\section{Abstract}


This article aims, through an experience report, at sharing reflections on the actions that were part of an extra-curricular project carried out in 2020 with the goal of strengthening health workers during the Covid-19 pandemic. Psychology students, resident psychologists and a professor took part in the experience, offering psychological care to thirteen workers from public health institutions, mostly nursing professionals, who sought the project on a spontaneous demand. During the sessions, the analysis of the day-to-day work and of individual and collective coping mechanisms was stimulated, a methodology based on Ergology. The converging themes that emerged in the sessions were: sense of responsibility, feeling of guilt and suffering at work; risk of contamination, social distance, and stigmas; work management and humanization of care. Finally, the importance of the project is considered both for the psychological attention and critical reflection of the workers about the labor processes.

Keywords: Mental health; COVID-19; Occupational health.

\section{Resumen}

Este artículo tiene como objetivo compartir reflexiones, a través de un relato de experiencia, sobre las acciones de un proyecto de extensión realizado en 2020 con la finalidad de fortalecer a los trabajadores de la salud durante la pandemia Covid-19. Participaron estudiantes de psicología, psicólogas residentes y una profesora, que ofrecieron atención psicológica a trece trabajadoras de instituciones públicas de salud, en su mayoría profesionales de enfermería, que buscaron el proyecto por demanda espontánea. Durante los encuentros se incentivó el análisis del trabajo diario y los mecanismos de afrontamiento individuales y colectivos, metodología basada en la Ergología. Los temas convergentes fueron: sentido de responsabilidad, sentimiento de culpa y sufrimiento en el trabajo; riesgo de contaminación, distancia social y estigmas; y gestión del trabajo y humanización del cuidado. Finalmente, se considera la importancia del proyecto para la recepción y reflexión crítica de las trabajadoras sobre los procesos de trabajo.

Palabras clave: Salud mental; COVID-19; Salud laboral.

\section{Introdução}

Desde o início de 2020, a pandemia do novo coronavírus (SARS-COV-2) figura no cenário global como uma situação crítica de saúde pública. A Coronavirus Disease 2019 (Covid-19), doença causada por esse vírus, é uma síndrome respiratória que, embora na maioria dos casos provoque apenas sintomas leves, pode evoluir para uma grave insuficiência respiratória e para a morte, especialmente em pessoas que pertencem a grupos de risco (Cucinotta \& Vanelli, 2020). Como consequência, ao longo de 2020, verificou-se um aumento expressivo na demanda por internações em enfermarias e unidades de terapia intensiva 
(UTI) nos hospitais e nos serviços de urgência no Brasil e no mundo.

Em contrapartida, na tentativa de controlar a rápida disseminação do vírus, governos adotaram medidas de distanciamento social, fechamento do comércio, proibição de acesso a parques e praias e obrigatoriedade do uso de máscaras em espaços públicos (Valente, 2020), conforme recomendações da Organização Mundial de Saúde (OMS) (WHO, 2020).

Por conseguinte, para além da saúde pública, o contexto pandêmico atravessou o campo social em suas mais diversas dimensões, impondo uma nova realidade de relações sociais, econômicas e culturais. Uma mudança dessa magnitude exigiu atenção especial à saúde mental, que costuma ser significativamente afetada em momentos de crise. Nesse sentido, estudos mostram as repercussões psicossociais da pandemia na população geral, como sentimentos de tristeza, nervosismo, ansiedade e alterações do sono (Almeida, Szwarcwald et al., 2021).

De maneira mais específica, sabe-se que em situações de emergências e desastres, profissionais que atuam diretamente no evento são expostos a excessivo desgaste físico e emocional.
Nesses casos, além dos longos turnos, pausas insuficientes e uso de equipamentos de proteção individual desconfortáveis, esse grupo enfrenta uma sobrecarga psicológica, tanto por precisarem se responsabilizar pela vida de outras pessoas, quanto pela complexidade e imprevisibilidade do trabalho (European Agency for Safetyand Health at Work, 2011).

Na pandemia da Covid-19, uma das principais categorias afetadas por essa complexa combinação de fatores foi a dos trabalhadores de saúde. Enquanto os holofotes da opinião pública propagam um discurso que associa sua atuação a um ato heroico (Baptista, 2020; Lima \& Cardim, 2021), a realidade desses profissionais na pandemia envolve, além da mudança nos processos de trabalho, lidar com mortes recorrentes, com a cobrança pela performance de sucesso e com o distanciamento de suas redes de suporte (Meireles, 2020; Leonel, 2021). Assim, estudos apontam que os impactos do atual contexto em suas vidas vão desde o medo aumentado de serem infectados até um sofrimento psíquico acentuado (Schmidt, Crepaldi, Bolze, Neiva-Silva \& Demenech, 2020; Oliveira, Oliveira-Cardoso, Silva \& 
Santos, 2020; Almeida, Nascimento et al., 2021).

Tal cenário nos levou à reflexão a respeito da necessidade de perceber esses trabalhadores de maneira dissociada da imagem de herói, considerando suas vivências de estresse, incerteza, medo, tristeza e ansiedade. Diante dessa inquietação, e entendendo que serviços de atendimento e acolhimento psicológico são peças-chave na promoção à saúde mental, desenvolvemos em 2020 um projeto de extensão com o propósito de acolher os sentimentos e reflexões de trabalhadores de saúde, a fim de potencializar a criação de estratégias de enfrentamento individuais e coletivas e fortalecer os sujeitos e as equipes.

O presente artigo é um relato da experiência dos autores enquanto participantes do projeto e objetiva não somente divulgar esta experiência, como também se configurar como um dispositivo disparador de novos olhares e análises a respeito da produção de subjetividade relacionada ao trabalho em saúde no contexto pandêmico.

\section{Metodologia}

O projeto de extensão apresentado consistiu na oferta de acolhimento Rev. Polis e Psique, 2021; 11(3): 255 - 274 psicológico a trabalhadores de duas instituições públicas de Belo Horizonte, um hospital público e uma Unidade de Pronto Atendimento (UPA). A divulgação nessas organizações foi realizada de modo distinto: no hospital, o projeto integrou as ações de um Programa Institucional para a promoção da saúde dos trabalhadores e foi divulgado pelo setor de comunicação social da organização. Na UPA, a parceria foi estabelecida com uma coordenadora de enfermagem que ficou responsável pela divulgação interna.

Os acolhimentos foram iniciados a partir de demanda espontânea das trabalhadoras, que preenchiam um formulário online com alguns dados de identificação pessoal acessado a partir de um $Q R$ code ou link divulgados nas instituições. Os encontros para o acolhimento foram realizados por meio de videochamadas em plataformas virtuais, ou por chamadas telefônicas, de acordo com o interesse e a disponibilidade das atendidas. Participaram da condução dos acolhimentos estudantes de graduação em Psicologia, psicólogos residentes de um hospital público e a docente coordenadora do projeto.

Em média foram realizados de três a quatro encontros com cada profissional, em datas e horários flexíveis, a depender 
da demanda de cada uma. Após cada sessão, os responsáveis pela condução registravam um relato do atendimento e suas impressões em um diário de bordo, cujo conteúdo foi apresentado e discutido entre todos os integrantes do projeto em reuniões semanais de supervisão, realizadas via plataforma virtual.

As sessões de acolhimentos, as discussões do grupo e as análises das experiências registradas nos diários de bordo tiveram como principal base teóricometodológica a Ergologia. Na abordagem ergológica, a atividade laboral é entendida como um uso de si, pois o indivíduo como ser é convocado no trabalho. A atividade laboral, por sua vez, envolve a singularidade do trabalhador, suas escolhas e arbitragens, assim como seu enfrentamento e reformulação das normas impostas de acordo com seus valores. O trabalhador é constantemente confrontado com a necessidade de fazer escolhas e assim tentar viver com saúde em um ambiente em parte imposto, em parte coercitivo, mas em parte modificável (Holz \& Bianco, 2014).

A Comunidade Ampliada de Pesquisa (CAP), modelo de análise dos processos de trabalho recomendado pela Política Nacional de Humanização
(Ministério da Saúde, 2004), também orientou nossas ações e reflexões. A CAP é um dispositivo de intervenção que preconiza uma compreensão ampliada das relações entre saúde e trabalho, sobre como as dinâmicas ocupacionais podem conduzir ao adoecimento e de quais enfrentamentos assertivos os trabalhadores criam no seu dia a dia. Trata-se de uma estratégia de construção de conhecimento a partir da troca de experiências entre profissionais que considera o saber produzido no e pelo trabalho e que tem por objetivo garantir a qualidade do cuidado e a promoção da saúde (Mori, Silva \& Beck, 2009).

Outra sustentação teórica que norteou as ações de acolhimento foi o guia destinado aos Primeiros Cuidados Psicológicos (PCP), produzido e difundido pela OMS (Organização Pan-Americana da Saúde [OPAS], 2015). Os PCP não são um atendimento psicológico profissional, mas sim uma resposta de apoio a pessoas de qualquer faixa etária que tenham sido afetadas por uma emergência ou desastre e necessitem de auxílio. O foco dos PCP é escutar, confortar e ajudar a pessoa a avaliar suas necessidades e preocupações e a reassumir o controle da sua própria situação. Nesse sentido, os acolhidos são 
incentivados a identificar habilidades e estratégias próprias que funcionaram no passado, além de redes de suporte.

Portanto, ao compreender a centralidade do trabalho na atualidade e seu caráter enquanto produtor de saúde, de identidade e subjetividade, assim como de sofrimento e adoecimento, consideramos que intervenções voltadas a promover uma análise crítica das experiências de trabalho feita pelos próprios trabalhadores são cruciais para ampliar seu poder de ação e potencializar a transformação e a humanização do cotidiano dos serviços.

Pelo fato de a experiência relatada ter surgido como uma atividade de extensão, e não como uma pesquisa com seres humanos, não houve submissão do projeto ao Comitê de Ética em Pesquisa e, portanto, o presente trabalho se trata apenas de uma exposição e reflexão a respeito da vivência dos autores e não apresenta citações diretas das falas das acolhidas, de maneira a preservar seu anonimato. A escolha metodológica pelo relato de experiência se baseia na ideia de que essa narrativa permite dar forma ao que foi vivido e investigar as questões que a experiência despertou (Domingos, 2016). Assim, as análises e discussões foram realizadas a partir da identificação de aspectos convergentes nos acolhimentos que irromperam nas reuniões dos extensionistas como uma realidade que não pode ser ignorada e precisa ser pensada.

\section{Resultados e Discussão}

A vivência relatada teve duração de cinco meses, entre abril e agosto de 2020, período das atividades de extensão. Nesse tempo, dezesseis trabalhadores de saúde (quatorze mulheres e dois homens) buscaram acolhimento com os extensionistas, sendo sete atuantes na UPA e nove no hospital geral. Após três desistências antes do início dos atendimentos, um total de treze profissionais foram acolhidas de forma individual ou em pequenos grupos. Todas se identificavam como mulheres e possuíam longa experiência em serviços de saúde, sendo que nove atuavam em equipes de enfermagem e as restantes eram uma médica, uma fisioterapeuta, uma fonoaudióloga e uma auxiliar administrativa.

A grande demanda da enfermagem por acolhimento psicológico foi um dos pontos que emergiu das reflexões dos participantes nas discussões. Essa dinâmica parece estar relacionada a fatores como: o grande contingente dessas trabalhadoras nos serviços de saúde, as 
longas jornadas de trabalho com o acúmulo de mais de um emprego, a menor autonomia no trabalho (especialmente no caso das técnicas de enfermagem) e uma intensa pressão e cobrança por parte de gestores, médicos, pacientes e familiares. No caso das profissionais da enfermagem, o processo de trabalho apresenta uma carga mental significativa, além da carga física, por lidarem cotidianamente e de modo intenso com os usuários e seus familiares, o que intensifica os impactos psicológicos vivenciados no ambiente hospitalar, principalmente em situações de sobrecarga como em situações de emergências e desastres (Kovács, 2010; Kiselyet al., 2020; Liu et al., 2020).

A análise dos acolhimentos permitiu ainda localizar outros pontos de convergência que parecem entremear a produção de subjetividade no trabalho em saúde em um contexto pandêmico. Estes pontos foram separados em três categorias analíticas apresentadas a seguir.

Senso de Responsabilidade, Sentimento de Culpa e Sofrimento no Trabalho

A mudança no cotidiano de trabalho e o aumento da ansiedade e do estresse foram questões que despontaram em todos os acolhimentos. Ao mesmo tempo em que se consideravam proativas
- algumas inclusive ocupando cargos de liderança - a maioria das mulheres que escutamos expressou sofrimento pela dificuldade, ou impossibilidade de manter o alto nível de desempenho exigido na nova conjuntura. Nas mais diversas ocupações, deparamo-nos com profissionais que acreditavam precisar dar conta de tudo, mesmo em situações extremas como uma pandemia.

Assim, quando julgavam ter falhado nessa missão, eram inundadas por um sentimento de culpa que nem sempre era verbalizado e que gerava sofrimento, desorganização e ansiedade. $\mathrm{O}$ senso de responsabilidade exacerbado parecia se transformar em um sentimento de culpa moralizante e opressor expresso de diversas formas: preocupação excessiva com os outros; dificuldade de estabelecer limites nas situações de trabalho e negligência no autocuidado (Autor, 2018). Preocupadas em resolver o possível e o impossível, as trabalhadoras acabavam por não fazer as pausas de descanso necessárias, assumiam funções que não lhes cabiam e se isolavam socialmente por não conseguir pedir ajuda. Uma das acolhidas, por exemplo, expressou que as situações em que se sentia mais ansiosa eram quando se sentia incapaz de resolver 
um problema sozinha e precisava de auxílio. Outra profissional queixava-se de não conseguir relaxar, apesar de estar de férias, pois se via responsável por reformular os protocolos de atendimento para o cenário pandêmico.

Segundo o referencial da Ergologia, "o trabalhador sempre reorganiza o trabalho que lhe é imposto, fazendo escolhas e executando-o de outra maneira" (Holz\& Bianco, 2014, p. 500). Tal reorganização é pautada nos valores do trabalhador e existem situações em que o indivíduo tem que arbitrar valores contraditórios. Ao escutar a experiência das trabalhadoras acolhidas, esse confronto entre os valores pessoais e institucionais aparece na trama do sofrimento. Em uma análise dos desafios enfrentados por profissionais de saúde na pandemia, Greenberg, Docherty, Gnanapragasam e Wessely (2020) apontam que a situação tende a favorecer problemas de saúde mental nesta população por acirrar decisões morais difíceis, como equilibrar suas próprias necessidades com as dos usuários e alinhar seu desejo e dever para com os pacientes, os familiares e os amigos. Essas decisões se tornam ainda mais difíceis em meio à pressão social que equipara profissionais de saúde a superheróis e a um ideário cristão que estimula a abdicação de si mesmo em prol do próximo.

Ademais, nos serviços de saúde há um predomínio do saber intervencionista biomédico e de práticas que visam o controle dos processos de trabalho, empreendidas pela Política da Qualidade para gestão dos riscos (Autor, 2018). Este saber sustenta as práticas de trabalho normatizantes em busca da normalidade na concepção de saúde, o que restringe o entendimento da subjetividade ao estritamente racional e rechaça a dimensão subjetiva do ser humano, habitado pela contradição, pelo não saber, vivendo situações paradoxais (Schraiber, 1996; Autor, 2017). Nesse contexto, é possível observar a dificuldade das profissionais em lidar com o que foge ao próprio controle, como falhas, inseguranças e a morte (Kovács, 2010). Uma das técnicas de enfermagem acolhidas, por exemplo, expressava dificuldade em lidar com seus sentimentos ambivalentes em relação a colegas e usuários do serviço, sentindo-se incomodada com o que considerava um paradoxo.

A questão da responsabilidade permeia a subjetividade das profissionais de saúde e aparece em outros estudos a respeito de sua atuação em contextos de pandemia. Em entrevistas com enfermeiras 
chinesas atuando na pandemia da Covid19, emergiu como tema a "forte responsabilidade e identidade como profissional de saúde" (Liu et al., 2020, p. 4, tradução livre). Já no trabalho de Honey e Wang (2012) com a pandemia de H1N1 na Nova Zelândia, enunciados de dever e responsabilidade para com os usuários ou colegas apareceram como principais motivos para que as enfermeiras entrevistadas assumissem turnos extras: "Senti que era meu dever trabalhar"; "Não queria decepcionar meus colegas" e "Queria ajudar minha unidade de trabalho" (p. 67, tradução nossa).

Ainda em relação à produção desses sentimentos no ambiente hospitalar, Silva (1998) observa que a organização dos processos de trabalho nos hospitais tende a individualizar responsabilidades que deveriam ser coletivas, o que acaba por fomentar esse processo de culpabilização. Além disso, há um sistema de vigilância operando nestes ambientes que "passa a fazer parte do comportamento do próprio profissional consigo e com os outros, responsabilizando as profissionais perante as situações inesperadas ou de fracasso terapêutico" (Autor, 2018, p. 465).
Uma das trabalhadoras acolhidas, por exemplo, demonstrava muita impaciência com comportamentos de seus colegas que ela considerava desatentos e displicentes e, concomitantemente, sentiase extremamente culpada por não conseguir dar conta de todo seu trabalho. Outra trabalhadora, ao mesmo tempo em que considerava certos colegas despreparados para atuar no contexto da pandemia, era acometida por inseguranças e angústias relativas à sua própria atuação nesse cenário. Uma terceira, ao se recusar a atuar nas alas da Covid-19 para preservar a filha pequena, foi acusada explicitamente pelos colegas de os estar abandonando. Em contrapartida, ela mesma parecia dividida entre sua responsabilidade como profissional e como mãe e acreditava que estava falhando nas duas.

Em todos os casos citados foi possível identificar trabalhadoras que transpareciam um profundo comprometimento e dedicação ao trabalho e, ainda assim, sentiam que não estavam fazendo o suficiente. Ademais, em vários acolhimentos, ao identificarem que estavam sofrendo com o trabalho, as profissionais falavam da necessidade de, apesar disso, continuar agindo 
normalmente, suportar as pressões e demonstrar força.

$\mathrm{Na}$ perspectiva ergológica e da CAP, uma análise de seu cotidiano de trabalho e das vivências pessoais permitiria às trabalhadoras ampliar seu poder de agir e manejar o sofrimento associado à atividade laboral. Nesse sentido, as intervenções que buscamos realizar ao longo dos acolhimentos estimulavam um exame crítico dos processos de trabalho e do contexto pandêmico sem precedentes, que afeta a todos. Tambémse incentivou o diálogo com colegas de trabalho para a identificação de estratégias de enfrentamento coletivas, além de ações que envolviam o autocuidado, o lazer $\mathrm{e}$ as redes de suporte social.

\section{Risco de Contaminação, Distanciamento} Social e Estigmas

Outro ponto manifesto em diversos relatos ouvidos foi a preocupação com o risco de contaminação por Covid-19 de si mesmas e dos familiares, colegas ou usuários. Uma das acolhidas considerava a estrutura física da unidade de trabalho inadequada, tendo em vista os quartos de descanso da equipe e os banheiros, enquanto outra demonstrou apreensão quanto a condutas irresponsáveis de alguns colegas no descarte e armazenamento de materiais.

O medo do contágio, a intensa preocupação em torno da carência de EPI e o aumento da sensação de vulnerabilidade foram identificados em diversos estudos com profissionais de saúde que trabalharam contra a Covid-19 (Oliveira et al., 2020; Leonel, 2021). O risco aumentado de contaminação, somado à recomendação de distanciamento social, parece isolar mais as profissionais, seja pela separação por iniciativa própria de familiares e amigos, como forma de protegê-los, seja por serem desencorajadas a interagir mais que o necessário com usuários e colegas no ambiente de trabalho.

Um terceiro fator que colabora para um maior isolamento desse grupo é a crença equivocada de que trabalhadores de saúde são mais susceptíveis a contrair e transmitir o vírus, o que gera um estigma que as afasta ainda mais do convívio social (Oliveira et al., 2020; Peuker\& Modesto, 2020; Leonel, 2021). Durante a experiência dos acolhimentos, por exemplo, uma técnica de enfermagem mencionou sentir hostilidade em seu serviço, vinda de profissionais que não atendiam setores com pacientes com Covid-19 e sempre tratavam os colegas 
desses setores como se estivessem contaminados.

Além do estigma social, nos chamou a atenção também a questão de como o medo da transmissão da doença afetou as relações sociais das trabalhadoras de maneira ampla, dificultando os relacionamentos interpessoais e intensificando o sofrimento (Kiselyet al., 2020; Almeida, Nascimento et al., 2021). Uma das profissionais demonstrava receio em se encontrar com o namorado e a sogra, por conta do risco de contágio. Outra acolhida compartilhou que os pais acreditavam não serem mais importantes em sua vida, uma vez que ela estava limitando as visitas por medo de contaminá-los. Uma terceira, ao praticar distanciamento de seus familiares dentro de casa, expressava um sentimento de solidão.

Nessa direção, evidencia-se um paradoxo: conforme comentado anteriormente, as profissionais de saúde são representadas pela mídia como heroínas que devem ser admiradas e ovacionadas; ao mesmo tempo, a atuação tida como heroica traz consigo medo, isolamento, estigma, além de intensificar a cobrança social por êxito profissional. Diante disso, os acolhimentos buscaram também promover a identificação da rede de apoio psicossocial dos sujeitos e coconstruir saídas que permitissem um maior suporte familiar e social, ainda que à distância.

Juntamente à dificuldade dessas trabalhadoras em lidar com falhas e enfrentar sua própria vulnerabilidade, o isolamento social imposto pela pandemia acabou por aumentar o seu sofrimento e talvez afastá-las ainda mais da busca por ajuda e acolhimento. Nesse sentido, a baixa procura pelo acolhimento psicológico por parte dos profissionais de saúde, realidade com a qual nos deparamos no projeto, poderia estar relacionada a uma associação entre fragilidade e sentimento de fracasso pessoal e à consequente dificuldade desses sujeitos em lidar com seus medos e inseguranças e de se colocarem como receptores de cuidado.

\section{Gestão do Trabalho e Humanização do Cuidado}

As situações de conflito na gestão do trabalho também foram relatadas pela maioria das acolhidas. Observamos que algumas profissionais, sobretudo as que trabalhavam diretamente no cuidado aos usuários com Covid-19, sentiam-se 
inseguras com relação ao apoio recebido por parte da organização em que trabalhavam. Esse sentimento se agravava nas situações em que identificavam carência de recursos humanos e materiais, tais como EPIs e planos de ação da organização para reduzir os riscos de contaminação. No entanto, em reuniões com membros da gestão, foi relatado que tal percepção era consequência de falta de informação e de uma comunicação mais assertiva e não de uma real carência de EPIs.

Esse desencontro explicita que a situação de desconfiança para com a organização associa-se comumente ao precário diálogo entre a gestão dos serviços e as profissionais de saúde. Apesar da maioria das trabalhadoras considerar que o apoio de seus colegas e lideranças contribuem para sua saúde mental, a situação de ter que trabalhar com recursos físicos ou de pessoal insuficientes, especialmente quando há a percepção de que isso é evitável, gerava sentimentos de frustração e desânimo (Greenberg et al., 2020).

Nesse sentido, uma técnica de enfermagem afirmava ter desistido de contatar a coordenação sobre o descarte inadequado de materiais porque sentia que suas denúncias não surtiam efeito. Outras trabalhadoras declararam não serem escutadas pelos gestores dos serviços, relatando falta de acolhimento da gestão a suas demandas, por vezes consideradas excessivas. Tal realidade é contrária ao que preconiza a Política Nacional de Humanização (PNH), que se fundamenta na indissociabilidade entre gestão e atenção em saúde e tem como diretriz a coparticipação e a corresponsabilização de gestores, profissionais e usuários nos processos de trabalho e na gestão do cuidado (Ministério da Saúde, 2004).

Outra diretriz da PNH é a valorização do trabalhador a partir da visibilidade de suas experiências e demandas, bem como sua inclusão nos processos coletivos de gestão (Ministério da Saúde, 2004). Entretanto, a partir do acolhimento das profissionais, podemos inferir a existência de fragilidade no processo democrático nos serviços de saúde, resguardando a importância das decisões hierarquizadas em momentos de emergência. Essa fragilidade acarreta situações como a da profissional acolhida que expressava insatisfação com a exigência, por parte da gestão, de cumprimento de metas que não foram flexibilizadas ou repensadas na conjuntura atípica da pandemia. Outra trabalhadora relatava cobrança de produtividade acima 
do possível por parte da coordenação, em um contexto de equipe reduzida e em detrimento da saúde mental das profissionais. Assim, a falta de diálogo e reconhecimento aparecem como fatores geradores de angústia e sofrimento (Sangy, 2017).

No entanto, vale ressaltar que apesar das dificuldades em lidar com as repentinas mudanças nos processos de trabalho e dos relatos de conflitos interpessoais, algumas acolhidas perceberam um aumento da solidariedade nas equipes. $\mathrm{O}$ estresse, medo $\mathrm{e}$ inseguranças mobilizaram a união e o processo de ajuda mútua no ambiente de trabalho, o que contribuiu para o enfrentamento dos desafios nesse novo cenário.

Tendo isso em vista, as intervenções realizadas durante os encontros não se restringiram a incentivar o autocuidado individual, mas caminharam na direção de fomentar o apoio mútuo, a corresponsabilização entre as equipes e o diálogo com a gestão. As estratégias de cuidados coletivos foram incentivadas, bem como uma comunicação mais assertiva e empática, de maneira a tentar resolver alguns impasses geradores de sofrimento (Sangy, 2017). Como resultado, ressalta-se que, apesar das fragilidades da gestão do trabalho, durante os acolhimentos, uma das técnicas de enfermagem expressou sentimentos de validação e satisfação ao relatar que sua coordenadora tomou atitudes concretas em relação às preocupações levantadas por ela. Outra acolhida expressou alívio ao partilhar com os colegas as sensações de angústia, medo e culpa que vivenciou ao retornar ao trabalho após alguns dias afastada, enquanto uma terceira afirmou que colegas de trabalho constituíam um de seus principais suportes sociais. Por fim, em vários momentos de um acolhimento em grupo, foi percebida a validação entre as trabalhadoras acerca das emoções experienciadas, o que gerou empatia com a experiência alheia e sentimento de se sentir compreendida.

\section{Experiências dos Extensionistas}

Apesar das experiências durante os encontros de acolhimento terem sido variadas e singulares, durante as discussões em grupo algumas afetações em comum despontaram de nossas vivências como extensionistas.

No caso dos psicólogos residentes, ao mesmo tempo em que desenvolviam 
seus recursos para enfrentar a pandemia na vida pessoal e no ambiente hospitalar onde atuavam, participavam do projeto, acolhendo profissionais com as quais partilhavam sentimentos e dificuldades. A insegurança e o medo se intensificaram diante da necessidade de se adequar às mudanças nos processos de trabalho. No entanto, por meio dos acolhimentos, da imersão em leituras sobre saúde do trabalhador e da participação nas reuniões do grupo de extensionistas, foi possível um amadurecimento de saídas criativas no próprio contexto laboral. Assim, os residentes participaram de forma mais ativa no diálogo com a gestão, compartilhando as decisões sobre escalas e organização do setor, apoiaram-se mutuamente e fortaleceram outros vínculos potentes no trabalho, além de visitarem esporadicamente o espaço de saúde mental do trabalhador promovido durante a pandemia no setor em que estavam alocados.

Além disso, as reflexões conjuntas propiciaram aos autores uma visão crítica a respeito dos processos de subjetivação no trabalho, especialmente na área da saúde, que podem ser motrizes para sofrimentos e ou adoecimentos, como também para a saúde mental. Neste sentido, a participação no projeto nos instigou a um olhar mais atento quanto às nuances da prática clínica que precisam ser cuidadas para não se tornarem prejudiciais à saúde dopróprio psicólogo.

$\mathrm{O}$ senso de responsabilidade e culpa, assim como as mudanças na rotina de trabalho, o distanciamento de amigos e familiares e o medo de contágio também fizeram parte da experiência pessoal dos extensionistas. Nesse contexto, apresentar e analisar tais aspectos nas reuniões virtuais de supervisão nos propiciou suporte e fortalecimento, de modo que esses encontros também constituíram um dispositivo de acolhimento potente.

Por fim, os integrantes do projeto compartilharam um senso de satisfação ao vislumbrar os impactos dos acolhimentos nas profissionais, auxiliando-as a enfrentar melhor as angústias impostas pela vivência pandêmica e a encontrarem suas próprias estratégias de enfrentamento não adoecedoras.

\section{Considerações Finais}

Profissionais de saúde atuando diretamente no combate à Covid-19 enfrentam inéditas e complexas demandas de trabalho e inúmeros desafios e dilemas, tanto no ambiente laboral, quanto pessoal e familiar. Assim, para além da figura 
heroica disseminada nas grandes mídias, é fundamental reconhecê-las como sujeitos que, em especial nesse momento, também demandam cuidados. Com tal propósito em vista, os autores desenvolveram em 2020 um projeto de extensão para oferecer acolhimento psicológico a trabalhadores de saúde de instituições públicas, entendendo que o acolhimento se torna fundamental no contexto de emergência sanitária, ao atuar como dispositivo de apoio e fortalecimento. Essa experiência, orientada pelas premissas teórico-metodológicos das Ergologia, da Comunidade Ampliada de Pesquisa e dos Primeiros Cuidados Psicológicos, se insere na prática da Clínica Ampliada, que tem como eixos fundamentais a compreensão da saúde integral e de seus determinantes sociais, a aposta na gestão compartilhada e participativa e a necessidade de suporte aos profissionais de saúde (Ministério da Saúde, 2009).

Durante os acolhimentos, buscou-se incentivar a análise do cotidiano de trabalho, a expressão de sentimentos e a identificação dos recursos de enfrentamento e da rede de apoio psicossocial das trabalhadoras, de forma a ajudá-las a lidar com as próprias dificuldades, com a complexidade e imprevisibilidade do contexto pandêmico e com o sofrimento laboral. Além disso, apostando que o fazer compartilhado é mais potente que uma abordagem individual e pontual, instigamos mecanismos de defesa coletivos no trabalho e a integração das equipes.

Nesse processo, algumas das saídas reavivadas ou inventadas pelas profissionais incluíram o aumento da abertura às trocas e o apoio mútuo entre colegas; a valorização de momentos de lazer, descanso e autocuidado; a busca por suporte familiar e social, ainda que por meios virtuais; reflexões e iniciativas em prol da corresponsabilização dentro das equipes de trabalho e melhoria do diálogo com a gestão.

A maioria das trabalhadoras atendidas verbalizou, ao fim do último encontro, satisfação e gratidão pelos acolhimentos, expressando se sentirem cuidadas e mais seguras após participarem do projeto. Algumas também ressaltaram que as discussões promovidas as ajudaram a perceber a importância do cuidado consigo mesmas e com os outros e a ampliar sua análise das situações de sofrimento e conflitos, pessoais e profissionais. 
O presente trabalho é fruto das discussões empreendidas durante as reuniões de supervisão do projeto, um espaço de diálogo em que a troca de ideias e o compartilhamento de afetações permitiu um aprendizado de todas as partes. Assim, este relato surgiu da necessidade de refletir sobre aquilo que, na experiência, irrompeu diante de nós como algo que requer atenção e exploração. Em linha com o dispositivo de três polos da Ergologia,nosso relato tem por intuito alimentar o conhecimento compartilhado ao promover uma interlocução entre os saberes técnicos e científicos da Psicologia Hospitalar e da Psicologia do Trabalho com as experiências e saberes imanentes às atividades - tanto das profissionais atendidas quanto dos extensionistas -, que resulta em uma renovação dos saberes formais e disciplinares, em uma postura ética e reflexiva.

Os limites do presente estudo se referem ao fato de este ser um relato de experiência de um projeto realizado por um período curto e no início da pandemia.Além disso, houve um número restrito de trabalhadorasacolhidas, sendo todas mulheres, com longa experiência na área da saúde, majoritariamente profissionais da enfermagem e atuantes em serviços de alta e de média complexidade em instituições públicas.

Ademais, algumas problematizações que emergiram da experiência de extensão não foram abordadas no presente trabalho, o que abre espaço para pesquisas futuras, como a tentativa de compreender a baixa procura dos trabalhadores aos serviços de saúde mental, mesmo em um momento de intenso sofrimento como o da pandemia.

Por fim, entendemos que o projeto de extensão cumpriu seu compromisso ético de promoção de saúde mental em trabalhadores de saúde e contribuiu significativamente para a formação dos envolvidos, permitindo a análise crítica da atuação do psicólogo em prol do cuidado à saúde mental do trabalhador em situações de emergências e desastre.

\section{Referências}

Almeida, V. R. S., Nascimento, D. C., Moura, J. C. V., Silva, J. M. S., Oliveira, D. R., Freitas, M. Y. G. S., \& Santos, C. L. R. (2021). Impacto psicossocial causado pela pandemia da covid-19 nos profissionais de saúde. Revista Baiana de Enfermagem, 35, e37900. doi:10.18471/rbe.v35.37900

Almeida, W. D. S. D., Szwarcwald, C. L., Malta, D. C., Barros, M. B. D. A., Souza, P. R. B. D., Azevedo, L. O., ... \& Silva, D. R. P. D. (2021). 
Mudanças nas condições socioeconômicas e de saúde dos brasileiros durante a pandemia de COVID-19. Revista Brasileira de Epidemiologia, 23. doi:10.1590/1980-549720200105

Baptista, R. (2020, 12 de maio). 'Heróis e guerreiros': senadores fazem homenagens no Dia do Enfermeiro. Agência Senado. Recuperado dehttps://www12.senado.leg.br/notici as/materias/2020/05/12/herois-eguerreiros-senadores-fazemhomenagens-no-dia-do-enfermeiro

Cucinotta, D., \&Vanelli, M. (2020). WHO Declares COVID-19 a Pandemic. Acta bio-medica: AteneiParmensis, 91(1), 157-160. doi:10.23750/abm.v91i1.9397

Domingos, J. C. (2016). Relatos de experiencia, en busca de un saber pedagógico. Revista Brasileira de Pesquisa (Auto)biográfica, 1(1), 14$30 . \quad$ doi:10.31892/rbpab2525426X.2016.v1.n1.p14-30

European Agency for Safety and Health at Work [EU-OSHA]. (2011). Emergency Services: A Literature Review on Occupational Safety and Health Risks. doi:10.2802/54768

Greenberg, N., Docherty, M., Gnanapragasam, S., \&Wessely, S. (2020). Managing mental health challenges faced by healthcare workers during covid-19 pandemic. BMJ 2020, 368, m1211.doi:10.1136/bmj.m1211

Holz, E. B., \& Bianco, M. D. F. (2014). Ergologia: uma abordagem possível para os estudos organizacionais sobre trabalho. Cadernos EBAPE.
BR, 12, 494-512. doi:10.1590/167939519106

Honey, M., \& Wang, W. Y. (2013). New Zealand nurses perceptions of caring for patients with influenza A (H1N1). Nursing in Critical Care, 18(2), 63-69. doi:10.1111/j.14785153.2012.00520.x

Kisely, S., Warren, N., McMahon, L., Dalais, C., Henry, I., \&Siskind, D. (2020). Occurrence, prevention, and management of the psychological effects of emerging virus outbreaks on healthcare workers: rapid review and meta-analysis. BMJ 2020, 369, m1642. doi:10.1136/bmj.m1642

Kovács, M. J. (2010). O sofrimento da equipe de saúde no contexto hospitalar: cuidando do cuidador profissional. O Mundo da Saúde, 34(4), 420-429. Recuperado dehttps://www.saocamilosp.br/pdf/mundo_saude/79/420.pdf

Leonel, F. (2021, 23 de março). Pesquisa analisa o impacto da pandemia entre profissionais de saúde. Fundação Oswaldo Cruz. Recuperado de https://portal.fiocruz.br/noticia/pesqu isa-analisa-o-impacto-da-pandemiaentre-profissionais-de-saude

Lima, B., \& Cardim, M. E. (2021, 1 de janeiro). 2020: o ano dos superheróis que vestem jalecos brancos. Correio Braziliense. Recuperado de https://www.correiobraziliense.com. br/brasil/2021/01/4897871-2020-oano-dos-super-herois-que-vestemjalecos-brancos.html

Liu, Y. E., Zhai, Z. C., Han, Y. H., Liu, Y. L., Liu, F. P., \&Hu, D. Y. (2020). Experiences of front-line nurses combating coronavirus disease-2019 
in China: A qualitative analysis. Public Health Nursing, 37(5), 757763. doi:10.1111/phn.12768

Meireles, G. (2020, 22 de maio). Profissionais da linha de frente encaram desafios de saúde mental na pandemia. Faculdade de Medicina da UFMG. Recuperado dehttps://www.medicina.ufmg.br/pro fissionais-da-linha-de-frenteencaram-desafios-de-saude-mentalna-pandemia/

Ministério da Saúde. (2004). HumanizaSUS - Política Nacional de Humanização: a humanização como eixo norteador das práticas de atenção e gestão em todas as instâncias do SUS. Recuperado dehttp://bvsms.saude.gov.br/bvs/publ icacoes/humanizasus_2004.pdf

Ministério da Saúde. (2009). HumanizaSUS - Clínica ampliada e compartilhada. Recuperado de https://bvsms.saude.gov.br/bvs/publi cacoes/clinica_ampliada_compartilh ada.pdf

Mori, M. E., Silva, F. H. D., \& Beck, F. L. (2009). Comunidade Ampliada de Pesquisa (CAP) como dispositivo de cogestão: uma aposta no plano coletivo. Interface (Botucatu), 13, 719-727. doi:10.1590/S141432832009000500023

Oliveira, W. A. D., Oliveira-Cardoso, É. A. D., Silva, J. L. D., \& Santos, M. A. D. (2020). Impactos psicológicos e ocupacionais das sucessivas ondas recentes de pandemias em profissionais da saúde: revisão integrativa e lições aprendidas. Estudos de Psicologia (Campinas), 37, e200066. doi:10.1590/1982$\underline{0275202037 \mathrm{e} 200066}$
Organização Pan-Americana da Saúde [OPAS]. (2015). Primeiros cuidados psicológicos: guia para trabalhadores de campo. Recuperado dehttps://www.paho.org/bra/dmdocu ments/GUIA_PCP_portugues_WEB. pdf

Peuker, A. C., \& Modesto, J. G. (2020). Estigmatização de profissionais de saúde. Enfrentamento da COVID-19 (tópico 4). Sociedade Brasileira de Psicologia, Ribeirão Preto, SP, Brasil. Recuperado dehttps://www.sbponline.org.br/enfre $\underline{\text { ntamento-covid19 }}$

Sangy, M. (2017). Saúde no Trabalho: intervenção psicossocial com trabalhadores de um hospital público. In Anais do II Congresso Interdisciplinar de Pesquisa, Iniciação Científica e Extensão do Centro Universitário Metodista Izabela Hendrix (pp. 1060-1076). Belo Horizonte, MG. Recuperado dehttp://izabelahendrix.edu.br/pesqui sa/anais/edicoes-anteriores/edicao$\underline{2017}$

Schmidt, B., Crepaldi, M. A., Bolze, S. D. A., Neiva-Silva, L., \&Demenech, L. M. (2020). Saúde mental e intervenções psicológicas diante da pandemia do novo coronavírus (COVID-19). Estudos de Psicologia (Campinas), 37, e200063. doi:10.1590/1982$\underline{0275202037 \mathrm{e} 200063}$

Schraiber, L. B. (1996). Ética e subjetividade no trabalho em saúde. Divulgação em Saúde para Debate, 12, 45-50.

Silva, C. O. (1998). Trabalho e subjetividade no hospital geral. 
Psicologia: ciência e profissão, 18(2), 26-33. doi:10.1590/S141498931998000200005

Valente, J. (2020, 01 de abril). Covid-19: veja como cada estado determina o distanciamento social. Agência Brasil. Recuperado dehttps://agenciabrasil.ebc.com.br/sa ude/noticia/2020-04/covid-19-vejacomo-cada-estado-determina-odistanciamento-social

World Health Organization. [WHO] (2020, 18 de maio). Overview of public health and social measures in the context of COVID-19. Recuperado dehttps://www.who.int/publications/i item/overview-of-public-health-andsocial-measures-in-the-context-ofcovid-19

Ana Luiza Fernandes Furtado possui graduação em Ciências Econômicas pela Universidade de São Paulo (2011) e em Psicologia pela Universidade Federal de Minas Gerais (2020).

E-mail: analuizafurtado@gmail.com

ORCID:https://orcid.org/0000-0001-9365$\underline{6479}$

Déborah David Pereira é psicóloga residente no programa de Residência Integrada Multiprofissional em Saúde da Universidade Federal de Minas Gerais (HC/UFMG).

E-mail: deborahdavidp@gmail.com

ORCID:https://orcid.org/0000-0001-5144$\underline{6430}$

Hugo Ribeiro Lanza é psicólogo residente no programa de Residência Multiprofissional em Saúde Mental da
Universidade Estadual de Campinas (Unicamp).

E-mail: hugo.rlanza@gmail.com

ORCID:https://orcid.org/0000-0001-9649$\underline{9448}$

Lucas Henrique de Carvalho é psicólogo pela Universidade Federal de Minas Gerais (UFMG), especialista em Saúde (HC/UFMG) e mestrando no Programa de Pós-graduação de Psicologia da UFMG.

E-mail: psicologolucash@ gmail.com

ORCID:https://orcid.org/0000-0002-6952$\underline{2224}$

Mateus Fonte Boa Viana é graduando em Psicologia na Universidade Federal de Minas Gerais (UFMG).

E-mail: mateusfbviana@ gmail.com

ORCID:https://orcid.org/0000-0002-6534$\underline{8679}$

Paula Cristina Carneiro do Prado é graduanda em Psicologia na Universidade Federal de Minas Gerais (UFMG).

E-mail:pccprado@gmail.com

ORCID:https://orcid.org/0000-0002-9993$\underline{4502}$

Mariana Pereira Santos é graduanda em Psicologia na Universidade Federal de Minas Gerais (UFMG).

E-mail: marianaps26@ gmail.com

ORCID:https://orcid.org/0000-0003-1480$\underline{9997}$

Camila Dulce Gorgulho Campos é psicóloga residente do Hospital das Clínicas da UFMG (HC/UFMG) com ênfase em Saúde do Idoso.

E-mail: camiladgcampos@ gmail.com ORCID:https://orcid.org/0000-0002-1568$\underline{1115}$

Daniele Souza Steglich é psicóloga especialista em Saúde do Idoso pelo programa de Residência Integrada 
Multiprofissional em Saúde da Universidade Federal de Minas Gerais (HC/UFMG).

E-mail: dani_steglich@ @otmail.com

ORCID:https://orcid.org/0000-0002-8533-

$\underline{2869}$

Gabriela Cunha Gonçalves é psicóloga residente no programa de Residência Integrada Multiprofissional em Saúde da Universidade Federal de Minas Gerais (HC/UFMG).

E-mail: gabi.cunhag@gmail.com

ORCID:https://orcid.org/0000-0001-9101-

1722.

Tereza Cristina Peixoto é doutora e Mestre em Saúde e Enfermagem, Psicóloga e Docente do departamento de Psicologia da Universidade Federal de Minas Gerais (UFMG).

E-mail: terezacp@ufmg.br ORCID:https://orcid.org/0000-0001-8826$\underline{5481}$

Submissão: 15/03/2021

$1^{\circ}$ avaliação: $12 / 07 / 2021$

Aceite: $30 / 08 / 2021$ 